\title{
Simulation of methane adsorption in diverse organic pores in shale reservoirs with multi-period geological evolution
}

\author{
Shangbin Chen ${ }^{1,2} \cdot$ Chu Zhang ${ }^{2}$ Xueyuan $\mathrm{Li}^{2}$ - Yingkun Zhang ${ }^{2}$. \\ Xiaoqi Wang ${ }^{2}$
}

Received: 17 December 2020/Revised: 5 March 2021 / Accepted: 13 April 2021/Published online: 11 May 2021

(C) The Author(s) 2021

\begin{abstract}
In shale reservoirs, the organic pores with various structures formed during the thermal evolution of organic matter are the main storage site for adsorbed methane. However, in the process of thermal evolution, the adsorption characteristics of methane in multi type and multi-scale organic matter pores have not been sufficiently studied. In this study, the molecular simulation method was used to study the adsorption characteristics of methane based on the geological conditions of Longmaxi Formation shale reservoir in Sichuan Basin, China. The results show that the characteristics of pore structure will affect the methane adsorption characteristics. The adsorption capacity of slit-pores for methane is much higher than that of cylindrical pores. The groove space inside the pore will change the density distribution of methane molecules in the pore, greatly improve the adsorption capacity of the pore, and increase the pressure sensitivity of the adsorption process. Although the variation of methane adsorption characteristics of different shapes is not consistent with pore size, all pores have the strongest methane adsorption capacity when the pore size is about $2 \mathrm{~nm}$. In addition, the changes of temperature and pressure during the thermal evolution are also important factors to control the methane adsorption characteristics. The pore adsorption capacity first increases and then decreases with the increase of pressure, and increases with the increase of temperature. In the early stage of thermal evolution, pore adsorption capacity is strong and pressure sensitivity is weak; while in the late stage, it is on the contrary.
\end{abstract}

Keywords Adsorption mechanism - Shale reservoir - Diverse pores · Multi-period geological evolution - Thermal evolution

Shangbin Chen

shbchencumt@hotmail.com

Chu Zhang

15152455900@163.com

Xueyuan Li

xy_li@cumt.edu.cn

Yingkun Zhang

m15512011623@163.com

Xiaoqi Wang

tb17010016b2@cumt.edu.cn

1 Key Laboratory of Coalbed Methane Resources and Reservoir Formation Process of the Ministry of Education, China University of Mining and Technology, Xuzhou 221116, China

2 School of Resources and Geoscience, China University of Mining and Technology, Xuzhou 221116, China

\section{Introduction}

China has become the third-largest shale gas producer in the world, establishing commercial mining in Fuling, Changning-Weiyuan, Zhaotong, and other districts (Dong et al. 2016a, b; Dong et al. 2016a, b; Zou et al. 2015, 2016, 2018). However, the main shale gas producing areas in China are still confined to the Sichuan Basin and its periphery. The production capacity is limited, the differences between wells are significant, input and output have not yet become matched, and large-scale exploitation still faces major difficulties (Chen 2016; Chen et al. 2012; Guo 2016). Paleozoic shale gas reservoirs in south China are over-matured, characterized by deep burial, wide distribution, and a complex reservoir pore structure (Chen et al. 2010; Guo and Zhang 2014; Nie et al. 2009). These 
characteristics cause difficulties in understanding the pore properties of the reservoirs and the characteristics of shale gas occurrence, presenting a barrier to overcoming the exploration and development bottleneck (Chen et al. 2020).

Shale gas reservoirs exhibit significant heterogeneity in space-time after through multi-stage and multi-type geological transformation (Pandey et al. 2018). Their pore types and structures, too, show great variation on the micro and macro scales (Cao et al. 2015; Jarvie et al. 2007; Loucks et al. 2009; Ross and Bustin 2007, 2008). The pores in shale can be divided into organic pores and inorganic pores. A large amount of methane exists in the pores of organic matter in the form of adsorption. The process of maturation plays a critical role in the development of the organic pores in shale gas reservoirs (Timothy et al. 2020). Thermal evolution experiments with rich organic matter have shown that pore volume and surface area increase with thermal maturity. Micropores are added gradually with the increase of thermal evolution degree, and the proportion of micropores reaches its maximum synchronously with the peak of the hydrocarbon production phase of the thermal evolution process (Chen and Xiao 2014; Mathia et al. 2016). While micropores increase with maturity, the ratio of mesopores and macropores decreases when the temperature and pressure increase. Pore diameters change most obviously in the thermal evolution process between $1.5-7.5 \mathrm{~nm}$ and $60-70 \mathrm{~nm}$. Micropores and mesopores are the main contributors to specific surface area (Chen et al. 2018). The combined results of experiments on the thermal evolution of shale and on methane adsorption under various evolutionary sequences have shown that pores are the most vital factor for methane adsorption performance in shale. With an increase in maturity, the TOC content gradually reduces, the microporous content gradually increases, and the increase in the microporous content during the thermal evolution process can significantly improve the capacity of methane adsorption (Singh 2011; Wang and Carr 2012; Singh et al. 2015; Pandey et al. 2018). However, the effect of the numbers of different types of pores appears to vary, and the augmentation effect of mesopores is smaller (Zhong et al. 2015). Thermal simulation experiments on oil shale samples suggest that the main diameter range first decreases and then increases with maturity. They also indicate that the generation of nanoscale cylindrical pores within organic matter is the primary cause of added porosity during mature hydrocarbon generation. Slit porosity at contacts between the organic matter and the skeleton particles, interlayer pores in clay minerals and dissolution pores also began to grow in the mature stage (Xue et al. 2015).

Adsorbed methane is an important part of shale gas, and the adsorption capacity of organic matter pores is stronger. It is of great significance to study the adsorption characteristics of methane in organic pores for improving shale gas productivity. Due to the complex and harsh geological conditions, it is difficult to meet the conditions in the process of experiment. More and more scholars use molecular simulation to study the adsorption characteristics of methane. Monte Carlo method and molecular dynamics method are common in the adsorption simulation system (Wu et al. 2015; Liu et al. 2016; Wang et al. 2016; Zhang et al. 2017). At present, molecular simulation methods have been used to study the adsorption characteristics of methane in organic pores, clay mineral pores and graphite pores (Xiong et al. 2017a, b, c, d), the competitive adsorption effect of $\mathrm{CO}_{2}$ and $\mathrm{CH}_{4}$ in kerogen (Sui and Yao. 2016), and the adsorption characteristics of methane on quartz with different wettability (Jiao et al. 2014). Molecular simulation has become an important supplement to experimental methods and an important tool to study adsorption characteristics.

Thermal evolution process leads to the development of multi-type, multi-shape and multi-scale organic pores in the reservoir. However, in the process of thermal evolution, the adsorption characteristics of methane in multi-type and multi-scale organic matter pores have not been fully understood. Based on the geological background and evolution of the Longmaxi Formation in the Changning area of the Sichuan Basin, computer-aided molecular simulations have been performed to investigate reservoir development of multi-type, multi-morphological pores and the molecular methane adsorption mechanism for multi-scale pores under a thermal evolution sequence. In this study, the following three problems are clarified: (1) the adsorption characteristics of methane in different types of pores with the same pore size; (2) the pore size of different types of pores with the strongest adsorption capacity; (3) the adsorption characteristics of methane in different evolution stages.

\section{Materials and methods}

\subsection{Background}

Previous studies have analyzed the geological conditions, such as geological structure, organic geochemistry and pore structure parameters, of Longmaxi Formation shale in Sichuan Basin. (Chen et al. 2017) (Fig. 1). According to IUPAC, shale pore size is classified into micropores $(<2 \mathrm{~nm})$, mesoporous pores $(2-50 \mathrm{~nm})$, and macropores $(>50 \mathrm{~nm})$. Histories of thermal evolution and hydrocarbon generation indicate a division into the immature stage, with $R_{\mathrm{O}}$ (vitrinite reflectance) values of $<0.5 \%$, a mature stage mainly producing condensate and moisture $\left(0.5 \%<R_{\mathrm{O}-}\right.$ $<1.2 \%$ ), and an over-mature stage mainly producing dry gas $\left(R_{\mathrm{o}}>0.5 \%\right)$ (Singh et al. 2013, 2016). The conditions 


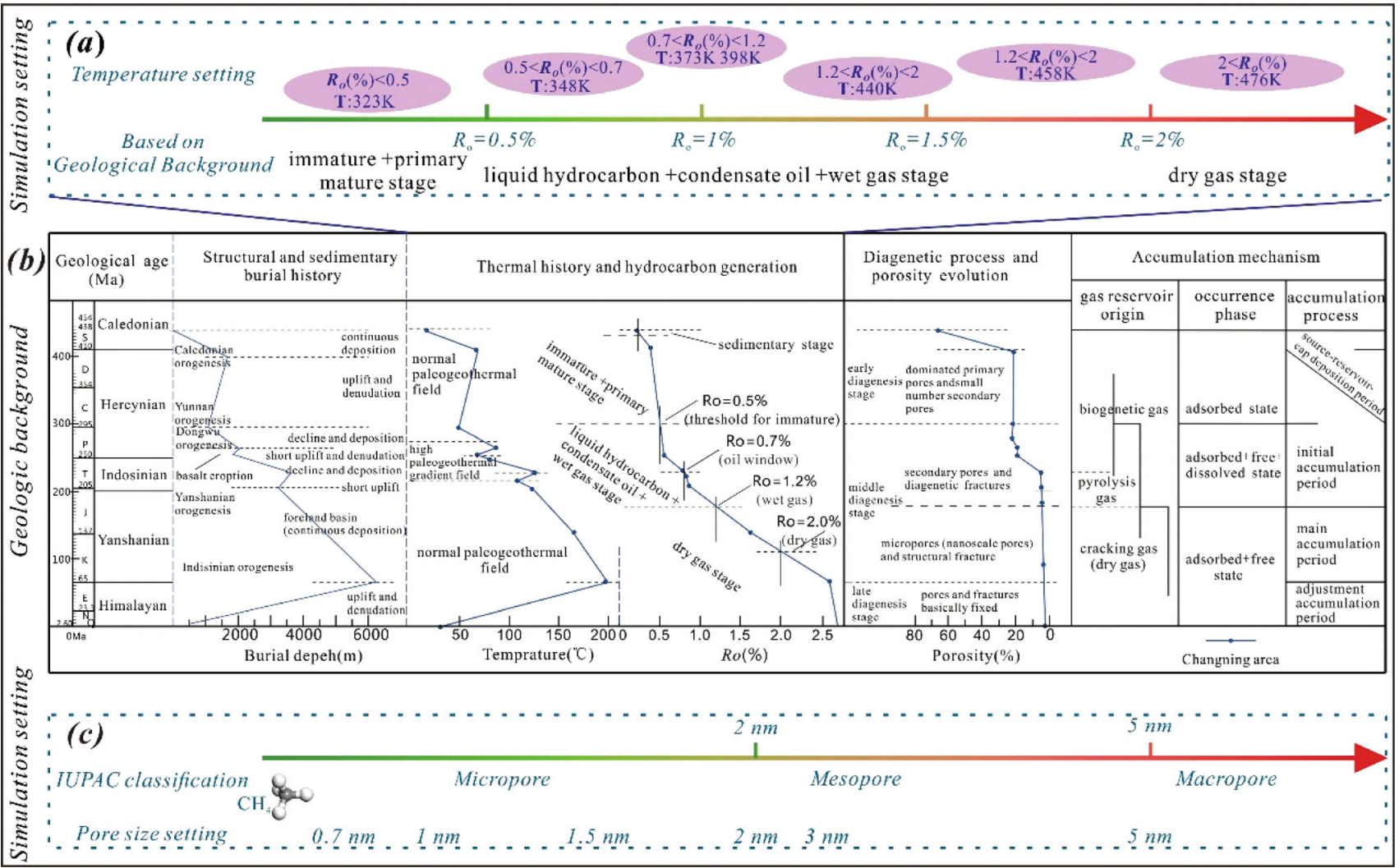

Fig. 1 Geological background and condition settings for the simulation ((b) is modified from (Chen et al. 2017))

used on the simulation were based these classification schemes as they relate to the Longmaxi Formation in the study area.

\subsection{Simulation methods}

\subsubsection{Models}

Due to prolong sedimentation, diagenesis, structure and other multi-type, multi-stage evolutionary effects of geological history, shale reservoirs develop extremely complex and heterogeneous pore systems (Fan and Liang 2019; Tang et al. 2019; Yang et al. 2016). It can be observed in the argon-ion polished scanning electron microscope image of shale rich in organic matter in the Longmaxi Formation, south Sichuan, that cylindrical pores, slit-shaped pores and slit-shaped pores with marginal grooves are ubiquitous in the reservoir. On the basis of the pore morphology found in the shale reservoir in this area, the pores are modeled as three simplified types: a homogeneous slit-pore model, a slit-pore model with grooves along its walls, and a cylindrical pore model. Cylindrical pores can be regarded as slit pores with curved sides. In order to make the physical properties of cylindrical pores and slit pores uniform, the physical properties (density) of homogeneous slit pores was taken as a reference, and the number of molecules on the upper and lower walls of a uniform slit pore were used as the basis for construction of a cylindrical pore (Fig. 2).

\subsubsection{Simulation details}

The sorption module in Materials Studio (Accelrys) software was utilized to research methane adsorption behavior with the macro-regular Monte Carlo method (GCMC), and a Compass force field was adopted as the force field type (Mosher et al. 2013; Sun 1998; Liu et al. 2018, 2019; Hu et al. 2010; Zhang et al. 2019). The interactions in the simulation include van der Waals force interaction and Coulomb force interaction. For the specific expression of van der Waals force interaction and Coulomb force interaction, refer to Zhang et al. (2019) and Liu et al. (2019).

The temperature points of the adsorption simulation were set depending on the process of maturation and evolution of the Longmaxi Formation (Fig. 1a). The pore size sequences were divided into less than $2 \mathrm{~nm}$ (micropores), 2-5 nm (mesopores) and greater than $5 \mathrm{~nm}$ (macropores) in light of the IUPAC classification (Fig. 1c). There were six pore size points and seven temperature points (Fig. 1b, c). Pressure ranged from 0.1 to $30 \mathrm{MPa}$, and constant temperature and constant pressure were used 


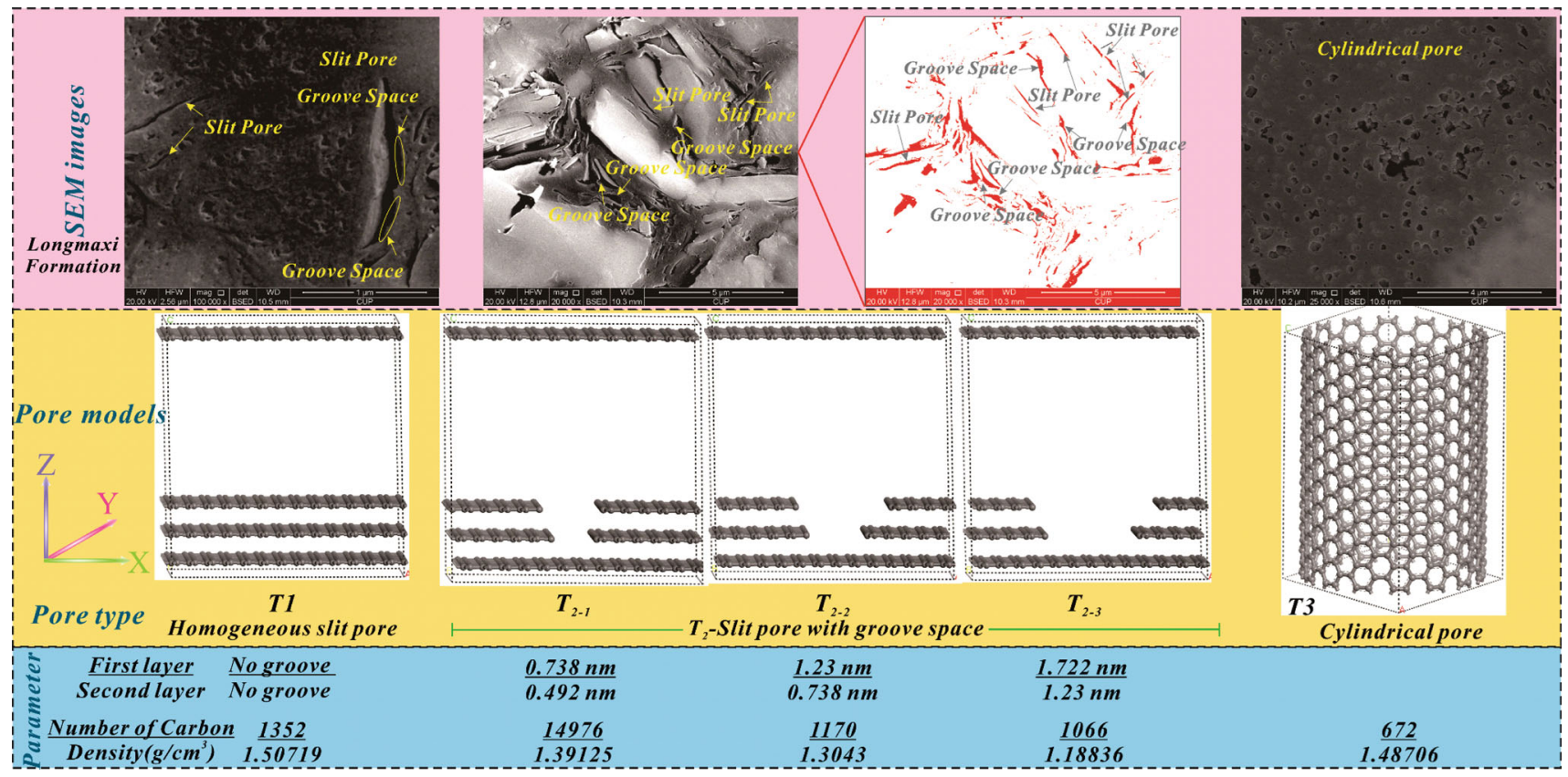

Fig. 2 Pore models and parameters

to calculate on a point-to-point basis during the simulation process, which was divided into 12 pressure points for calculation. The thermodynamic characteristics and distribution of methane in pores were studied by molecular dynamics simulation using the stable configuration obtained after adsorption. The calculations for the molecular dynamics were made with the Focite module, adopting the same force field and intermolecular force settings as used previously. The canonical ensemble (NVT) was adopted, and an Andersen thermal bath was used to control the temperature. A 0.5-ns molecular dynamics calculation with a step length of $1 \mathrm{fs}$ was carried out to determine the thermodynamic properties.

\subsubsection{Excess adsorption amount}

Absolute adsorption is defined as the quantity of gas present only in an adsorbed state (Mosher et al. 2013). When the temperature is lower than the critical temperature, the absolute adsorption amount represents the real adsorption amount. In shale formations, the methane adsorption becomes excessive when the temperature exceeds the critical temperature of methane (The critical temperature of methane is $191 \mathrm{~K}$ and the critical pressure is $4.6 \mathrm{MPa}$ ). In other words, absolute adsorption amount includes both gas molecules adsorbed on the pore wall in the form of adsorption phase and the gas molecules existing in the form of gas phase in the adsorption zone (near the pore wall) when the temperature exceeds the critical temperature. For excessive adsorption, the absolute adsorption amount is not the real adsorption amount. Therefore, under supercritical conditions, the excess adsorption capacity should be used to characterize the adsorption amount rather than the absolute adsorption capacity. Mosher and Gibbs have provided precise definitions of excessive adsorption (Mosher et al. 2013; Gibbs 1928). Excessive adsorption is defined as the additional amount of gas adsorbed per unit pore volume compared with the amount of gas in the same volume of a given pore without pore walls (Mosher et al. 2013). The excess adsorption amount only includes gas molecules adsorbed on the wall in the form of adsorption phase. The excess adsorption amount is equal to the absolute adsorption amount when the experimental temperature is lower than the critical temperature of the gas, whereas the excess adsorption amount is not equal to the absolute adsorption amount when the experimental temperature is higher than the critical temperature of the gas. Also, the difference between excess adsorption and absolute adsorption amount increases with the increasing experimental pressure when the temperature is higher than the critical temperature of the gas (Zhang et al. 2019). In this paper, the excess adsorption amount is used to express the adsorption amount. It can be found that it is reasonable to use excess adsorption amount to represent the real adsorption amount, which is in good agreement with the experimental results (Fig. 3). The calculation formula of excess adsorption amount is as follows:

$N_{\text {(excess) }}=N\left(V_{\mathrm{p}}+V_{\mathrm{c}}\right) \times \rho_{\mathrm{g}}=N-V_{\mathrm{g}} \times \rho_{\mathrm{g}}$ 


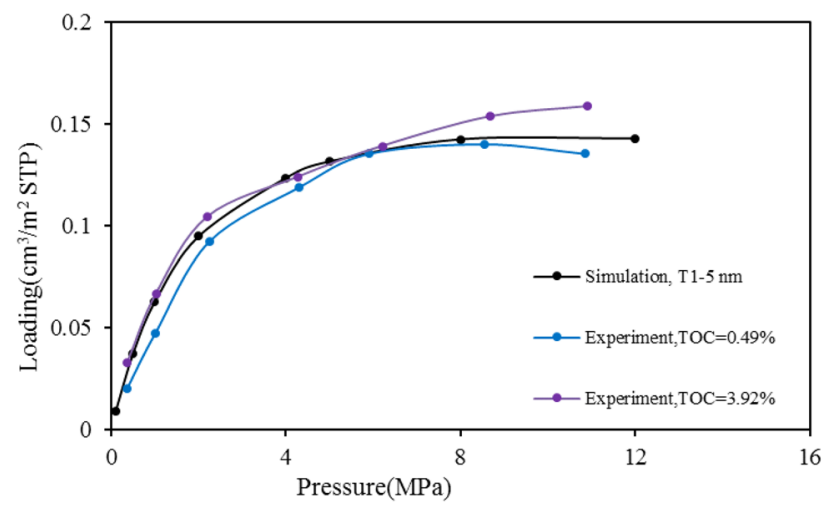

Fig. 3 Excess adsorption isotherm from simulation and experiments (the experimental data were reported by Bi et al. $(2014,2016)$ )

where, $N$ is the total amount of gas, which is fixed for the fixed model, $\mathrm{mmol} / \mathrm{g} ; V_{\mathrm{p}}$ is the adsorbed phase volume which was occupied by some gas phase molecules, $\mathrm{cm}^{3} ; V_{\mathrm{c}}$ is the gas phase volume, $\mathrm{cm}^{3} ; V_{\mathrm{g}}$ is the free volume, approximately equal to the free volume of the pore, which is fixed for the fixed model and can be calculated by Connolly Surface in the simulation software, $\mathrm{cm}^{3} ; \rho_{\mathrm{g}}$ is the density of the free gas, which is calculated by the $\mathrm{P}-\mathrm{R}$ equation of state and is only related to temperature, $\mathrm{g} / \mathrm{cm}^{3}$. It is worth mentioning that $\rho_{\mathrm{g}}$ will increases with the increase of pressure and may exceed $N$. Therefore, it is possible that the excess adsorption capacity is negative (Figs. $8 \mathrm{~b}$ and 9e). The fundamental reason for this phenomenon is that the volume of adsorbed phase occupied by gas molecules varies with temperature and pressure, and we use fixed free volume to represent the volume of gas phase and the volume of adsorbed phase occupied by gas molecules. The reason for this is that we cannot determine the volume of adsorbed phase occupied by gas molecules, which is a difficult problem in adsorption science.

\subsubsection{Probe molecule}

Free volume is an essential parameter for determining the excess adsorption capacity in GCMC adsorption simulation. In GCMC simulation, confirmation of the free volume is usually achieved by introducing diverse molecules one by one into the pore interior as probes. The choice of probe molecules has a great influence on the accuracy of the simulation results. Since helium gas was utilized as the probe molecule in methane isothermal adsorption experiment used to obtain the free volume of experimental samples (Ji et al. 2012; Zhang et al. 2012), the free volume of pores was obtained by selecting helium as the probe molecule in this simulation to maintain consistency between simulation and experiment.

\section{Results and discussion}

\subsection{Analysis of simulation accuracy}

The results for isothermal methane adsorption at $\mathrm{T}_{1}$-type (slit) pores in the simulation and experiments were compared (Fig. 3). The simulated excess adsorption capacity matched well with the experimental results, confirming the reliability of the pore model used in the simulation.

The molecular radius of the helium probe used in this study is $0.13 \mathrm{~nm}$, which is smaller than that of methane $(0.19 \mathrm{~nm})$. A helium probe can detect a finer pore space than can methane. Therefore, the accessible volume measured by helium probe is greater than the volume accessible for methane, and the calculated free volume is correspondingly larger than that of methane (Fig. 4).

Helium gas and methane were therefore respectively used as probe molecules to acquire diverse data on free pore volume, and corresponding adsorption curves for the two probes were compared (Fig. 5). The amount of adsorption in $\mathrm{T}_{2-1}$ (grooved slit) pores calculated with a helium probe is less than with a methane probe. The amount of adsorption calculated for $\mathrm{T}_{1}$-type pores using the two kinds of probes is almost the same; this is because $T_{1}$ type pores have a homogeneous structure, and there are no tiny spaces within them that methane molecules are not able to enter, unlike in the interior of $\mathrm{T}_{2-1}$-type pores.

\subsection{Methane adsorption characteristics of different pore types}

Figure 6 illustrates the comparative methane adsorption behaviors of the five morphological types of pores with the same pore size conditions. The molecular distribution of methane has two states. One is where methane molecules are gathered and accumulated near the wall of the pore area by the potential energy function of pore wall adsorption. Methane in this area includes adsorption-phase methane molecules and some free-phase methane molecules. The free-phase methane in the region is the cause of the decline in the adsorption curve. The molecular distribution pattern of methane is similar to that of the pore wall surface. Poregroove methane has a concave distribution in the groove space, similar to the shape of the groove space (Fig. 6a). Within cylindrical pores, methane near the pore surface has a circular distribution along the pore wall (Fig. 6c). The other molecular distribution state is where methane molecules are less affected by the pore wall potential energy. This occurs where inter-molecular methane interactions occur far away from the pore wall. These molecules are dispersed, in free phase and have random distribution pattern. 


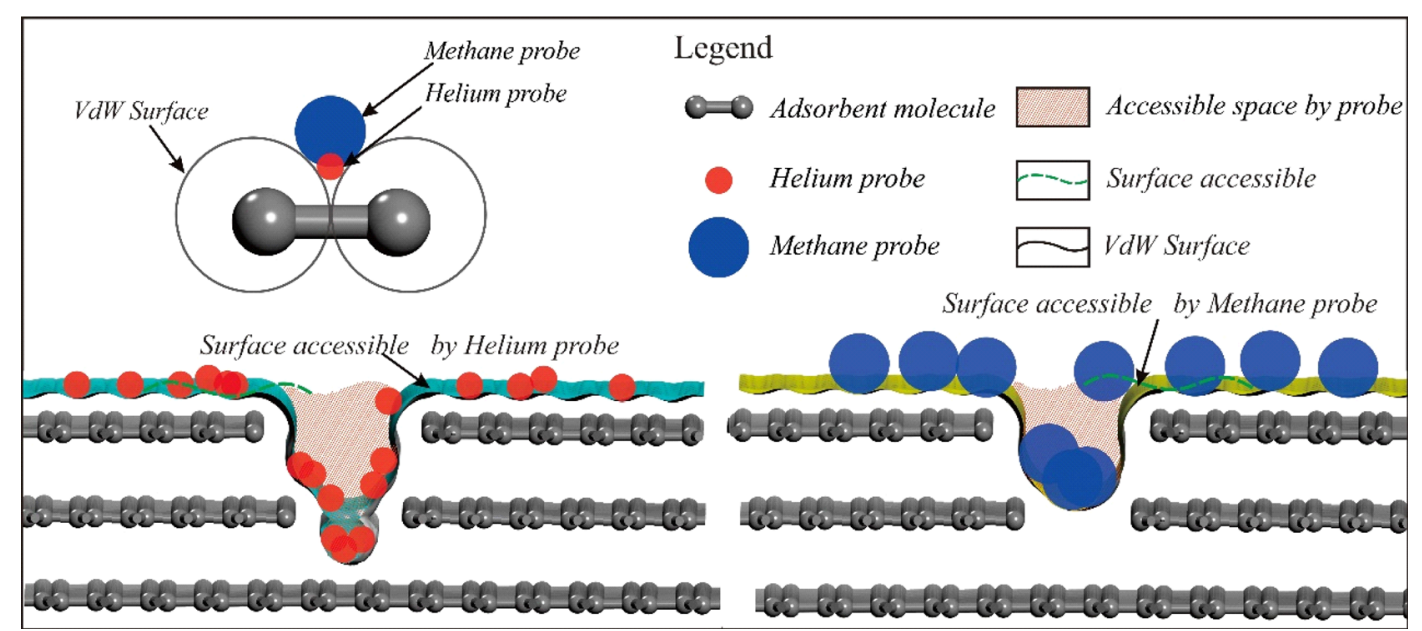

Fig. 4 Pores seen by different probes

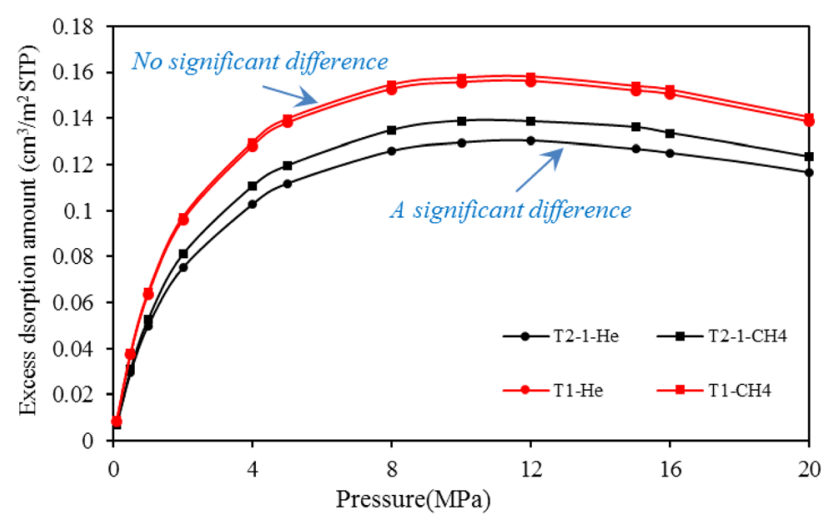

Fig. 5 Excess adsorption amount with different probe molecules

During adsorption, methane density is always higher at the position where the potential energy is the lowest (Liu et al. 2018; Charoensuppanimit et al. 2015; Hasanzadeh et al. 2010). There are peak densities at symmetrical positions at both ends and inside the slit-shaped pore methane density distribution curve because the potential energy of the pore wall is strongest near the pore wall region. The density peak reflects the methane adsorption layer near the pore wall with the most methane adsorption (Fig. 6a). In addition, we can also see that $\mathrm{T}_{2-1}, \mathrm{~T}_{2-2}$ and $\mathrm{T}_{2-}$

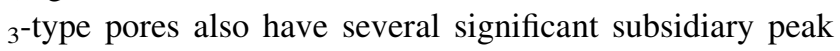
positions inside the pore wall. $\mathrm{T}_{2-1}$-type pores exhibit only one subsidiary peak, as methane molecules cannot enter the second-layer groove space inside these pores because a pore space needs to be greater than $0.492 \mathrm{~nm}$ for methane molecules to be adsorbed. $T_{2-2}$ and $T_{2-3}$-type pores each have two subsidiary peak positions, corresponding to their two-layer groove space; the larger the amount of methane adsorption in the groove space, the higher the methane density peak. The methane density distribution curve for cylindrical pores only has a single density peak at symmetrical positions at both ends, reflecting the adsorbed methane layer along the pore wall. This reaches a significantly smaller density value than do the curves for slitshaped pores (Fig. 6b).

Figure 7a shows isotherms of the methane adsorption capacity in the five types of pores with three different morphologies. Under different pressure conditions, the methane adsorption capacity of the slit pore with groove space is larger than that of the slit pore and cylindrical pore without groove space. It indicates that the presence of groove space has a significant additional effect on methane adsorption. When the growth rate of the four slit-shaped pore models is compared with the cylindrical pores under equal pressure conditions, it can be seen that the existence of groove space greatly influenced the pore methane adsorption capacity. The incremental growth rate compared with that in cylindrical pores reached more than $120 \%$ when the groove space opening size was $1.722 \mathrm{~nm}$, showing a major improvement in methane adsorption capacity (Fig. 7b). Therefore, it can be considered that the micro grooves on the pore wall can greatly improve the methane adsorption capacity of the pores. The adsorption capacity of methane increases with the increase of groove space.

For temperatures greater than $398 \mathrm{~K}$ (corresponding to $R_{\mathrm{O}}>1.2 \%$ ), the adsorption curve at pressures greater than $10 \mathrm{MPa}$ was used to carry out further fitting analysis (Fig. 7c, d). From this, it is found that when groove space is formed and enlarges inside a pore, the slope of the curve fitting equation and the absolute value of the quadratic coefficient follow an auxetic law, showing that the presence of groove space enhances the pressure-sensitivity of the methane adsorption capacity of the pore. Multi-stage evolution over the course of the geological history of a reservoir results in a complex, irregular pore morphology. 
(a)

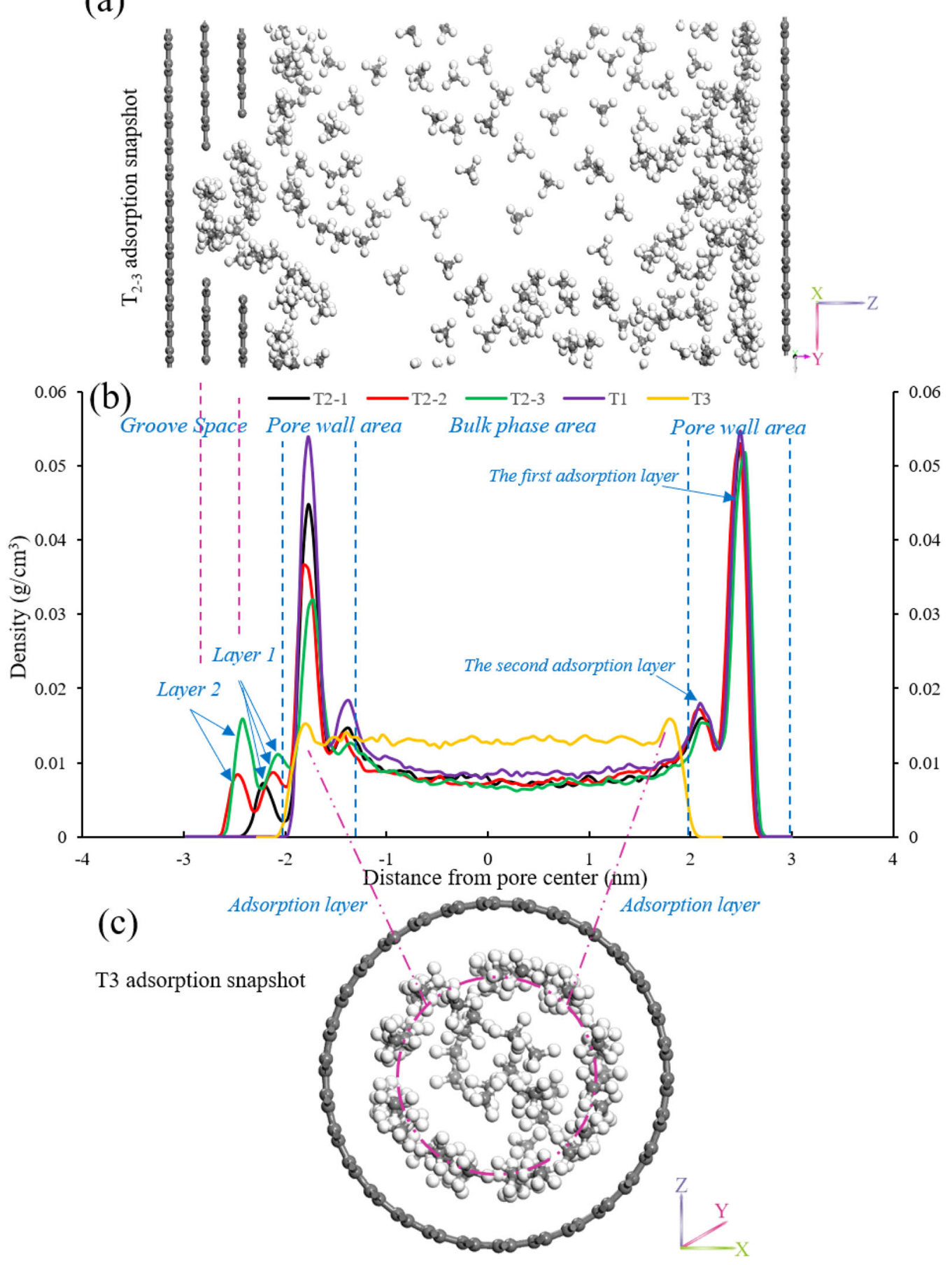

Fig. 6 Methane density and snapshot of different pore types

Such pores are more sensitive to pressure, and more irregular pores are more affected by pressure.

\subsection{Methane adsorption characteristics at different pore scales}

Figure 8a and $\mathrm{b}$ show isotherms of excess methane adsorption in different pore size bands. For slit-shaped pores less than $2 \mathrm{~nm}$ in diameter, when the pore size is less than $2 \mathrm{~nm}$, when the pore size increases, the methane adsorption capacity increases; for those larger than $2 \mathrm{~nm}$, methane adsorption capacity decreases as the pore size increases. Cylindrical pores, conversely, exhibit no obvious regularity.

However, an insufficient division of pore diameter can obscure the variation law of the amount of pore adsorption 


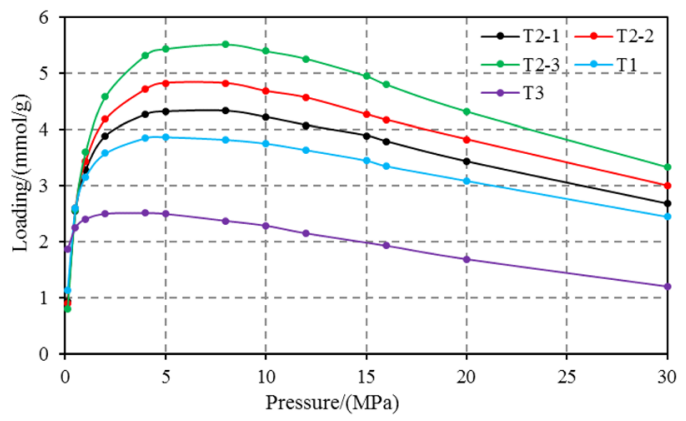

(a)

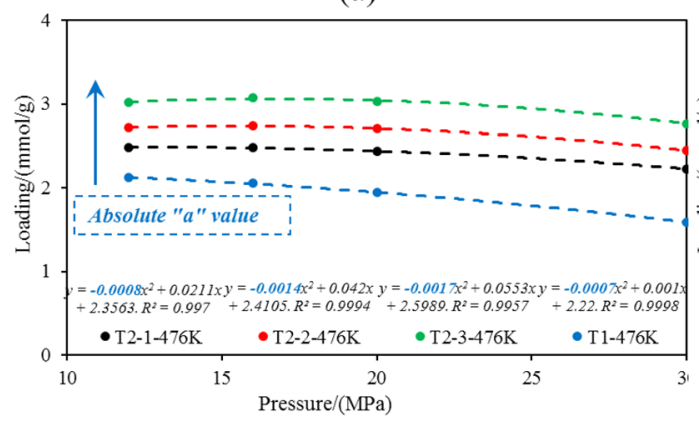

(c)

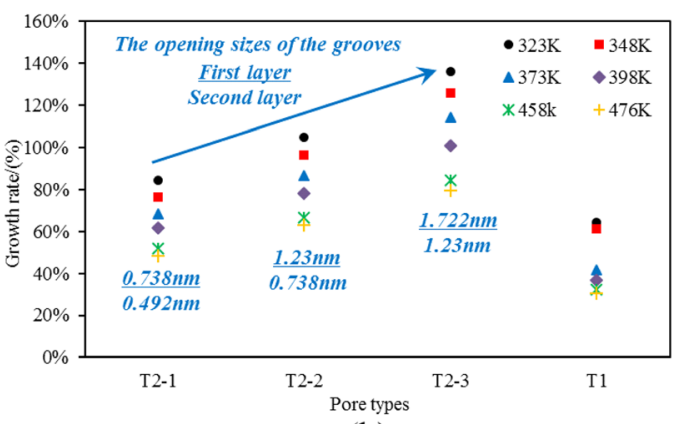

(b)

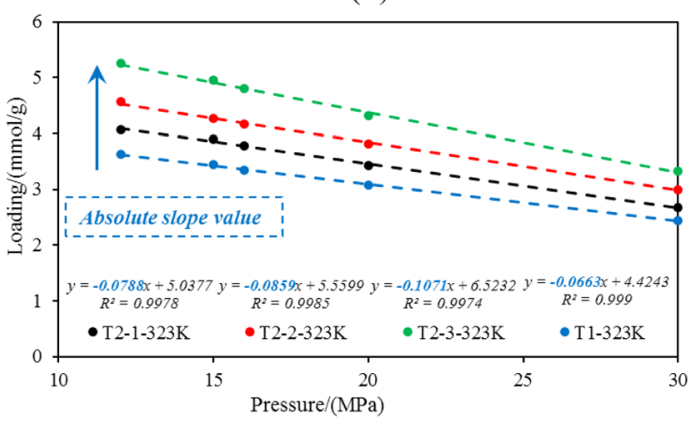

(d)

Fig. 7 Methane adsorption characteristics of different pore types

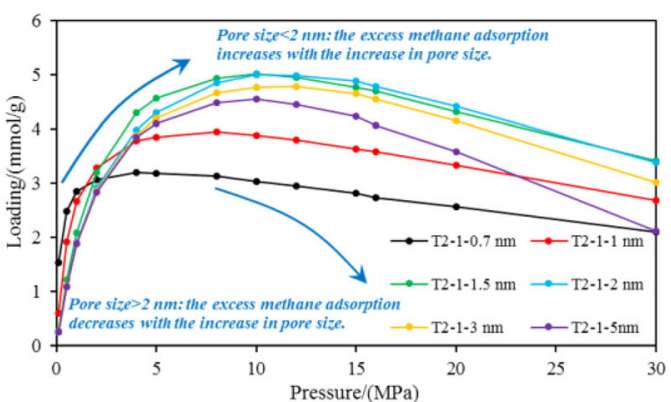

(a)

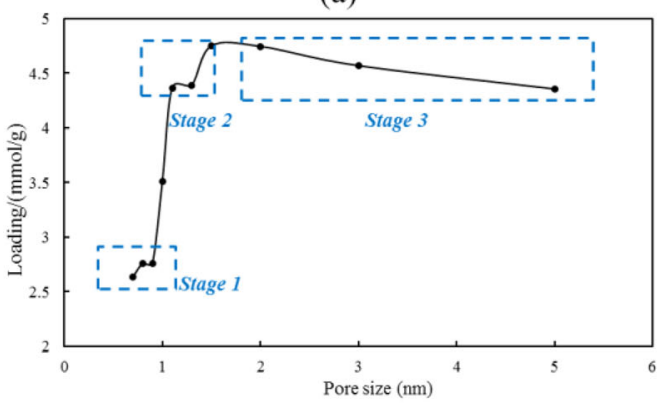

(c)

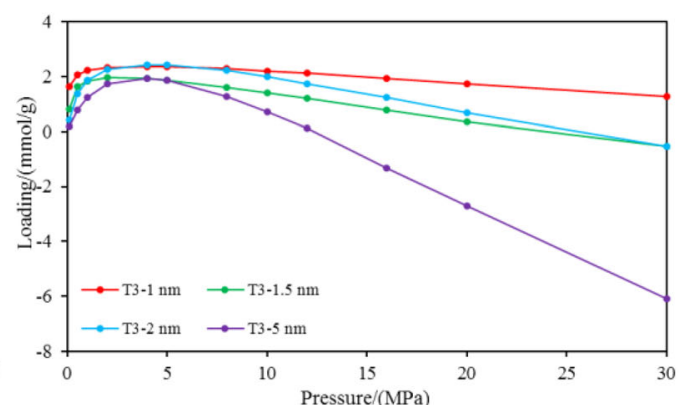

(b)

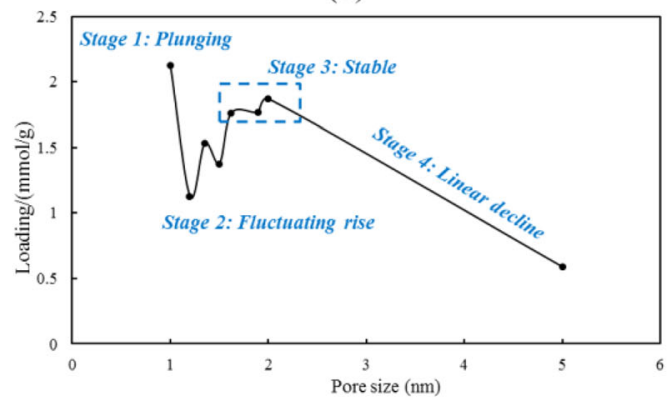

(d)

Fig. 8 Variation in the amount of adsorption with pore size

in some pore diameter intervals. Therefore, more accurate relationship between adsorption capacity and pore size can be obtained by further subdividing the pore size range (Fig. 8c, d). As we can see, when using the more subdivided pore size ranges, the variation law of adsorption capacity observed is different from that concluded above. The variation in the adsorption capacity of slit-shaped pores with pore size shows a ternary-form distribution: within the aperture range of $0.7-0.9 \mathrm{~nm}$, when the pore size increased, the adsorption changed little and increased 
slightly; it then shot up when the pore size is $1 \mathrm{~nm}$ before suddenly slowing down its increasing trend after passing $1.3 \mathrm{~nm}$; in the pore size range above $1.5 \mathrm{~nm}$, the adsorption capacity followed a law of stable decrease with the increase of pore size. The variation law of cylindrical pores with pore diameter is different from that of slit-shaped pores, though it also shows a ternary-form distribution: within the diameter range of 1-1.9 $\mathrm{nm}$, the amount of adsorption shows a certain volatility with an increase in pore diameter; after $1.9 \mathrm{~nm}$, the adsorption decreases rapidly and linearly with an increase in pore size. However, it can be implied from the combined results for slit-shaped and cylindrical pores that the pore size range most favorable for methane adsorption capacity is around $2 \mathrm{~nm}$.

\subsection{Pore adsorption characteristics under the thermal evolution sequence}

The adsorption simulation results for the various thermal evolution temperature point settings are shown in Fig. 9. The results show that the forms of the methane adsorption curves for the three types of pores are roughly the same, all showed a tendency of increasing first and then decreasing with an increase in pressure. For temperature points corresponding to the thermal evolution sequence, the amounts of adsorption of the three types of pores all decreased with an increase in temperature. This occurs because methane adsorption is an exothermic process, and an increase in temperature will aggravate the molecular movement of methane, thus hindering methane adsorption.

The methane adsorption capacity of the grooved slitshaped pores is larger than that of homogeneous slit-shaped pores, and the adsorption capacity increases gradually with an increase in groove space. Earlier studies have shown that methane cannot enter space with an opening size less than or equal to $0.492 \mathrm{~nm}$ and that pore space openings contributing to the adsorption capacity need to be larger than $0.492 \mathrm{~nm}$ (Zhang et al. 2019). For the slit-shaped pores with groove space, there is a difference in curve morphology between temperatures less than $398 \mathrm{~K}$ (corresponding to $R_{\mathrm{O}}<1.2 \%$ ) and greater than $398 \mathrm{~K}$ (corresponding to $R_{\mathrm{O}}>1.2 \%$ ). When the temperature is lower than $398 \mathrm{~K}$, the maximum adsorption capacity is reached only at $5 \mathrm{MPa}$, and the process of reaching the maximum adsorption capacity is faster than that when the temperature is higher than $398 \mathrm{~K}$. After reaching the maximum adsorption capacity, the adsorption capacity began to decrease, and the decrease rate decreased with the increase of temperature. When the temperature was greater than $398 \mathrm{~K}$, the adsorption curve became relatively gentle, and the maximum adsorption capacity occurred at a pressure of $12 \mathrm{MPa}$ or $16 \mathrm{MPa}$. The adsorption capacity then began to decline very gradually (Fig. 9a-d). This indicates that the pore is strongly adsorbant in the low-temperature stage of thermal evolution, but the amount of gas that can be adsorbed in this stage is greatly affected by pressure and the capacity for gas storage is weak, that is, a change in lithostatic stress will have a great influence on its gasbearing capacity. In the high-temperature stage of thermal evolution, pore adsorption performance decreases, but the adsorbed gas content is less affected by pressure in this stage, and the gas storage performance is stronger and more stable (Zhang et al. 2019).

The amount of methane adsorption in cylindrical pores is smaller than in slit-shaped pores, indicating that cylindrical pores have weaker adsorption performance under the same temperature and pressure state. Unlike with slitshaped pores, When the pressure was $4 \mathrm{MPa}$, the adsorption amount reached a maximum in cylindrical pores, then began to decline, and the rate of decline decreased with an increase in temperature (Fig. 9e). At the same temperature, adsorption in cylindrical pores decreased faster than in slitshaped pores, confirming that cylindrical pores have weaker adsorption ability than slit-shaped pores. Similarly to slit-shaped pores, the curve morphology differs between temperatures less than and more than $398 \mathrm{~K}$ (corresponding to $R_{\mathrm{o}}<1.2 \%$ and $R_{\mathrm{o}}>1.2 \%$, respectively). When the temperature is greater than $398 \mathrm{~K}$, the pressure of maximum adsorption capacity increases. There is an intersection point in the cylindrical pore methane adsorption curve. The amount of adsorption is negatively correlated with temperature at the pressure less than at the intersection, whereas it is positively correlated with temperature at the pressure greater than that at the intersection. It is also found that the intersection point shifts to the right with increasing temperature when the temperature is greater than $398 \mathrm{~K}$ (corresponding to $R_{\mathrm{O}}>1.2 \%$ ), again showing that pore methane adsorption performance has higher stress sensitivity under low-temperature conditions, consistent with the conclusion in Sect. 3.2.

\section{Conclusions}

This study shows that the pore morphology and the change of temperature and pressure in the process of thermal evolution have an influence on the adsorption characteristics of organic pores. The groove space inside the organic pores can greatly improve the methane adsorption capacity. The pore with pore size of about $2 \mathrm{~nm}$ has the strongest adsorption capacity for methane. The pore adsorption capacity first increases and then decreases with the increase of pressure, and increases with the increase of temperature. In the early stage of thermal evolution, pore adsorption capacity is strong and pressure sensitivity is weak, while in 


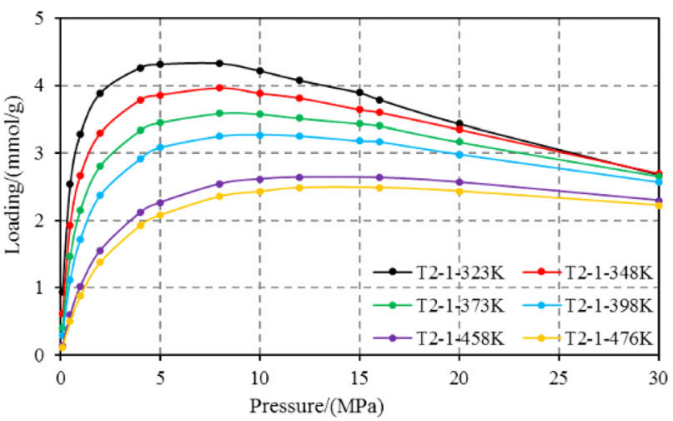

(a)

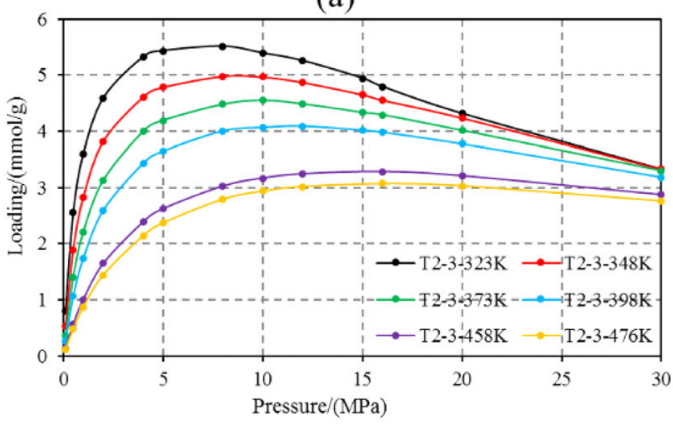

(c)

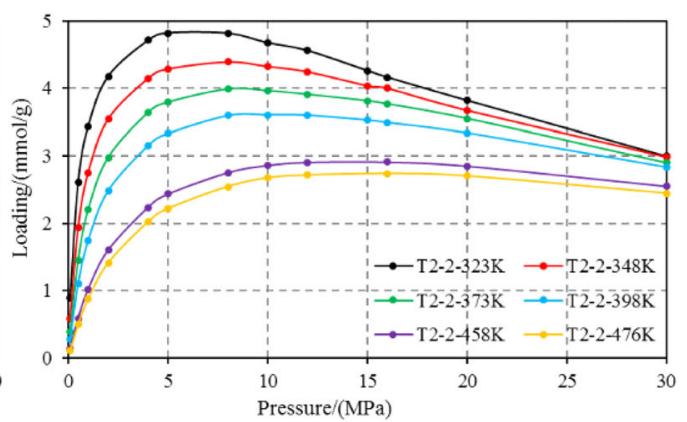

(b)

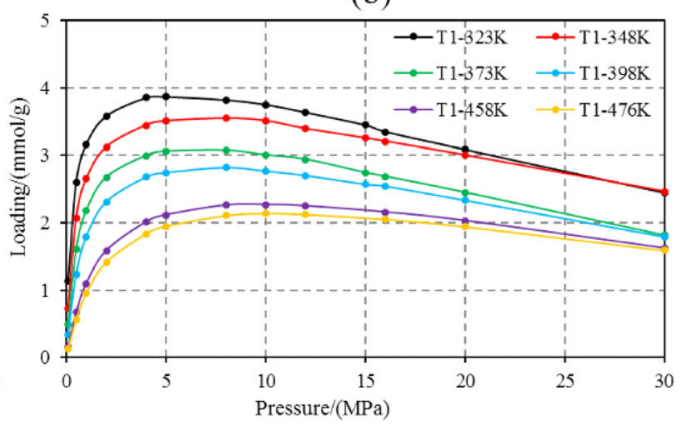

(d)

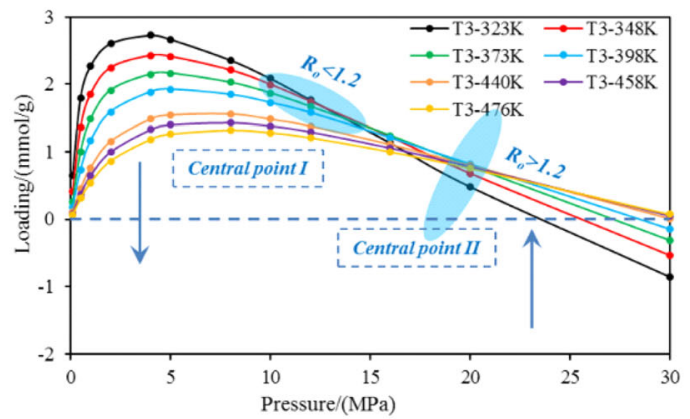

(e)

Fig. 9 Amount of methane adsorption under conditions corresponding with a thermal evolution sequence

the late stage of thermal evolution, pore adsorption capacity is on the contrary.

This will help researchers understand the adsorption characteristics of adsorbed gas in the process of thermal evolution, and lay a foundation for understanding the dynamic changes of adsorbed gas in the process of thermal evolution and the dynamic transformation of adsorbed gas and free gas. Based on this study, we believe that in the study of molecular diffusion and percolation mechanism of shale gas based on various adsorption desorption models, the morphological parameters of pore structure should be considered to make the model more accurate. At present, the understanding of pore structure evolution in the process of thermal evolution is not clear. In the process of thermal evolution, the change of pore morphology, temperature and pressure will affect methane adsorption. Therefore, the further research should pay attention to the coupling of these three factors and other factors on the dynamic control effects of adsorption, so as to get the research results that fit the real geological conditions as much as possible.

Authors' contributions SC makes substantial contributions to the development of ideas; CZ, XL, YZ and XW make substantial contributions to the development of analysis or interpretation.

Funding This work was supported by the National Natural Science Foundation of China (Nos. 41772141; 41972171), the Natural Science Foundation of Jiangsu Province (BK20181362), and the Priority Academic Program Development of Jiangsu Higher Education Institutions (PAPD).

Availability of data and material Not applicable.

Code availability The software applied in this paper is Materials Studio 2017, and we can get access to it through the link of https:// 
www.3ds.com/products-services/biovia/products/molecular-model ing-simulation/biovia-materials-studio/.

\section{Declarations}

Conflict of interest The authors declare that they have no known competing financial interests or personal relationships that could have appeared to influence the work reported in this paper.

Open Access This article is licensed under a Creative Commons Attribution 4.0 International License, which permits use, sharing, adaptation, distribution and reproduction in any medium or format, as long as you give appropriate credit to the original author(s) and the source, provide a link to the Creative Commons licence, and indicate if changes were made. The images or other third party material in this article are included in the article's Creative Commons licence, unless indicated otherwise in a credit line to the material. If material is not included in the article's Creative Commons licence and your intended use is not permitted by statutory regulation or exceeds the permitted use, you will need to obtain permission directly from the copyright holder. To view a copy of this licence, visit http://creativecommons. org/licenses/by/4.0/.

\section{References}

Bi H, Jiang Z, Li P, Cheng L, Zeng C, Xu Y et al (2014) Adsorption characteristic and influence factors of Longmaxi shale in southeastern Chongqing. Nat Gas Geosci 25(2):302-310

Bi H, Jiang Z, Li J, Peng L, Lei C, Pan Q et al (2016) The OnoKondo model and an experimental study on supercritical adsorption of shale gas: a case study of on Longmaxi shale in southeastern Chongqing, China. J Nat Gas SciEng 35:114-121

Cao T, Song Z, Wang S, Xia J (2015) A comparative study of the specific surface area and pore structure of different shales and their kerogens. Sci China Earth Sci 58:510-522

Charoensuppanimit P, Mohammad SA, Robinson RL Jr, Gasem KAM, (2015) Modeling the temperature dependence of supercritical gas adsorption on activated carbons, coals and shales. Int J Coal Geol 138:113-126

Chen S (2016) Study review on microstructure and adsorption heterogeneity of shale reservoir. Coal SciTechnol 44(6):23-32

Chen J, Xiao X (2014) Evolution of nanoporosity in organic-rich shales during thermal maturation. Fuel 129(4):173-181

Chen S, Zhu Y, Wang H, Liu H, Wei W, Luo Y et al (2010) Research status and trends of shale gas in China. Acta Petrol Sin 31(4):689-694

Chen S, Zhu Y, Wang H, Liu H, Wei W, Fang J (2012) Structure characteristics and accumulation significance of nanopores in Longmaxi shale gas reservoir in the southern Sichuan Basin. J China Coal Soc 37(3):438-444

Chen S, Zhu Y, Si C, Han Y, Fu C, Fang J (2017) Hydrocarbon generation and shale gas accumulation in the Longmaxi formation, southern Sichuan Basin, China. Mar Pet Geol 86:248-258

Chen S, Zuo Z, Moore TA, Han Y, Uwamahoro C (2018) Nanoscale pore changes in a marine shale: a case study using pyrolysis experiments and nitrogen adsorption. Energy Fuel 32(9):9020-9032

Chen Z, Liu X, Yang J, Little E, Zhuo Y (2020) Deep learning-based method for SEM image segmentation in mineral characterization, an example from Duvernay Shale samples in Western Canada Sedimentary Basin. ComputGeosci 138:104450

Dong D, Zou C, Dai J, Huang S, Zheng J, Gong J et al (2016b) Suggestions on the development strategy of shale gas in China. J Nat Gas Geosci 1(6):413-423
Dong D, Wang Y, Li X, Zou C, Guan Q, Zhang C et al (2016a) Breakthrough and prospect of shale gas exploration and development in China. Nat Gas Ind 3(1):12-26

Fan B, Liang S (2019) Deep-lacustrine shale heterogeneity and its impact on hydrocarbon generation, expulsion, and retention: a case study from the upper triassicYanchang formation, Ordos Basin, China. Nat Resour Res 28(1):241-257

Gibbs W (1928) The collected works of J. Willard Gibbs. Longmans, Greeen and Company, New York, p 55

Guo T (2016) Key geological issues and main controls on accumulation and enrichment of Chinese shale gas. Petrol Explor Dev 43(3):317-326

Guo T, Zhang H (2014) Formation and enrichment mode of Jiaoshiba shale gas field, Sichuan Basin. Petrol Explor Dev 41(1):28-36

Hasanzadeh M, Alavi F, Feyzi F, Dehghani MR (2010) Simplified local density model for adsorption of pure gases on activated carbon using Sutherland and Kihara potentials. MicroporousMesoporous Mater 136(1-3):1-9

Hu H, Li X, Fang Z, Ning W, Li Q (2010) Small-molecule gas sorption and diffusion in coal: molecular simulation. Energy 35(7):2939-2944

Jarvie DM, Hill RJ, Ruble TE, Pollastro RM (2007) Unconventional shale-gas systems: the Mississippian Barnett Shale of northcentral Texas as one model for thermogenic shale-gas assessment. AAPG Bull 91(4):475-499

Ji L, Zhang T, Milliken KL, Qu J, Zhang X (2012) Experimental investigation of main controls to methane adsorption in clay-rich rocks. ApplGeochem 27(12):2533-2545

Jiao H, Dong M, Liu Z, Xin Y, Han X (2014) Molecular dynamics simulation of methane adsorption with presence of water on different wettability quartz surface. J China Univ Petrol Ed Nat Sci 38(5):178-183

Liu Y, Zhu Y, Li W, Xiang J, Wang Y, Li J et al (2016) Molecular simulation of methane adsorption in shale based on grand canonical Monte Carlo method and pore size distribution. J Nat Gas SciEng 30:119-126

Liu Y, Zhu Y, Liu S, Li W, Tang X (2018) Temperature effect on gas adsorption capacity in different sized pores of coal: experiment and numerical modeling. J Pet SciEng 165:821-830

Liu J, Li S, Wang Y (2019) Molecular dynamics simulation of diffusion behavior of $\mathrm{CH}_{4}, \mathrm{CO}_{2}$, and $\mathrm{N}_{2}$ in mid-rank coal vitrinite. Energies 12(19):3744. https://doi.org/10.3390/ en12193744

Loucks RG, Reed RM, Ruppel SC, Jarvie DM (2009) Morphology, genesis, and distribution of nanometer-scale pores in siliceous mudstones of the Mississippian Barnett Shale. J Sediment Res 79:848-861

Mathia EJ, Bowen L, Thomas KM, Aplin AC (2016) Evolution of porosity and pore types in organic-rich, calcareous, Lower ToarcianPosidonia Shale. Mar Pet Geol 75:117-139

Mosher K, He J, Liu Y, Rupp E, Wilcox J (2013) Molecular simulation of methane adsorption in micro- and mesoporous carbons with applications to coal and gas shale systems. Int $\mathbf{J}$ Coal Geol 109-110:36-44

Nie H, Tang X, Bian R (2009) Controlling factors for shale gas accumulation and prediction of potential development area in shale gas reservoir of South China. Acta Petrol Sin 30(4):484-491

Pandey B, Pathak DB, Mathur N, Jaitly AK, Singh AK, Singh PK (2018) A preliminary evaluation on the prospects of hydrocarbon potential in the carbonaceous shales of Spiti and Chikkim formations, Tethys Himalaya, India. J GeolSoc India 92:427-434

Ross DJK, Bustin RM (2007) Shale gas potential of the lower Jurassic Gordondale member, northeastern British Columbia, Canada. Bull Can Petrol Geol 55:51-75 
Ross DJK, Bustin RM (2008) Characterizing the shale gas resource potential of Devonian-Mississippian strata in the Western Canada sedimentary basin: application of an integrated formation evaluation. AAPG Bull 92:87-125

Singh PK (2011) Geological and petrological considerations for coal bed methane exploration: a review. Energy Source Part A 33:1210-1220

Singh PK, Singh MP, Singh AK, Arora M, Naik AS (2013) Prediction of liquefaction behavior of East Kalimantan coals of Indonesia: an appraisal through petrography of selected coal samples. Energy Source Part A 35:1728-1740

Singh AK, Singh MP, Singh PK (2015) Microstructural relation of macerals with mineral matter in Eocene coal. Energy Source Part A 37:1089-1097

Singh PK, Rajak PK, Singh VK, Singh MP, Naik AS, Raju SV (2016) Studies on thermal maturity and hydrocarbon potential of lignites of Bikaner-Nagaur basin, Rajasthan. Energy Explor Exploit 34(1):140-157

Sui H, Yao J (2016) Molecular simulation of $\mathrm{CO}_{2} / \mathrm{CH}_{4}$ competitive adsorption in kerogen. J China Univ Petrol Ed Nat Sci 40(2):147-154

Sun H (1998) COMPASS: an ab initio force-field optimized for condensed-phase applications overview with details on alkane and benzene compounds. J PhysChem B 102:7338-7364

Tang X, Jiang S, Jiang Z, Li Z, He Z, Long S et al (2019) Heterogeneity of PaleozoicWufeng-Longmaxi formation shale and its effects on the shale gas accumulation in the Upper Yangtze Region, China. Fuel 239:387-402

Timothy IA, Bolivia V, Anthony RK (2020) Multimodal imaging and machine learning to enhance microscope images of shale. ComputGeosci 145(105493):1-14

Wang G, Carr TR (2012) Methodology of organic-rich shale lithofacies identification and prediction: a case study from Marcellus Shale in the Appalachian basin. ComputGeosci 49(Complete):151-163

Wang X, Zhai Z, Jin X, Wu S, Li J, Sun L et al (2016) Molecular simulation of $\mathrm{CO}_{2} / \mathrm{CH}_{4}$ competitive adsorption in organic matter pores in shale under certain geological conditions. Petrol Explor Dev 43(05): 772-779

Wu H, Chen J, Liu H (2015) Molecular dynamics simulations about adsorption and displacement of methane in carbon nanochannels. J PhysChem C 24:13652-13657
Xiong J, Liu X, Liang L, Zeng Q (2017c) Investigation of methane adsorption on chlorite by grand canonical Monte Carlo simulations. Petrol Sci 14(1):37-49

Xiong J, Liu X, Liang L, Zeng Q (2017d) Methane adsorption on carbon models of the organic matter of organic-rich shales. Energy Fuel 31(2):1489-1501

Xiong J, Liu X, Liang L, Zeng Q (2017a) Adsorption of methane in organic-rich shale nanopores: an experimental and molecular simulation study. Fuel 200:299-315

Xiong J, Liu X, Liang L, Zeng Q (2017b) Adsorption behavior of methane on kaolinite. IndEngChem Res 56(21):6229-6238

Xue L, Yang W, Zhong J, Xu Y, Chen G (2015) Porous evolution of the organic-rich shale from simulated experiment with geological constrains, samples from Yanchang formation in Ordos Basin. ActaGeol Sin-Engl 89(5):970-978

Yang W, Zhu Y, Liu S, Rui Z (2016) Methane adsorption measurements and modeling for organic-rich marine shale samples. Fuel 172:301-309

Zhang T, Ellis GS, Ruppel SC, Milliken K, Yang R (2012) Effect of organic-matter type and thermal maturity on methane adsorption in shale-gas systems. Org Geochem 47(6):120-131

Zhang Y, He Y, Yang Y, Wu K (2017) Molecular simulation of shale gas adsorption in organic-matter nanopores. Nat Gas Geosci 28(1):146-155

Zhang C, Chen S, Liu Y, Chen S, Li X (2019) Mechanism of methane adsorption on groove space in organic matter surface. MolSimul 45(3):186-198

Zhong J, Chen G, Lv C, Yang W, Xu Y, Yang S et al (2015) Experimental study of the impact on methane adsorption capacity of continental shales with thermal evolution. Nat Gas Geosci 26(7):1414-1421

Zou C, Dong D, Wang Y, Li X, Huang J, Wang S et al (2015) Shale gas in China: characteristics, challenges and prospects (I). Petrol Explor Dev 42:753-767

Zou C, Dong D, Wang Y, Xinjing LI, Huang J, Wang S et al (2016) Shale gas in China: characteristics, challenges and prospects (II). Petrol Explor Dev 43:182-196

Zou C, Yang Z, He D, Wei Y, Li J, Jia A et al (2018) Theory, technology and prospects of conventional and unconventional natural gas. Petrol Explor Dev 45(4):604-618 